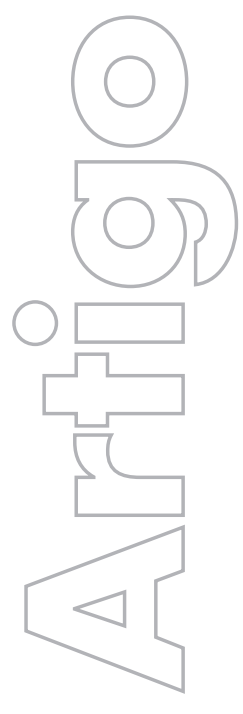

revista

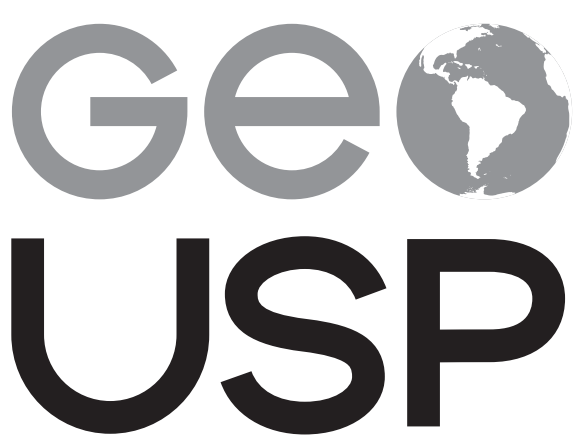

espaço e tempo

Volume $23 \cdot n^{\circ} 1$ (2019)

ISSN 2179-0892
"Quanta decepção me esperava fora dos limites da nossa casa": geografias afetivas do habitar em Lavoura arcaica, de Raduan Nassar

Carlos Roberto Bernardes de Souza Júnior UFG e-mail: carlosroberto2094@gmail.com

p. $076-094$

Como citar este artigo:

SOUZA JÚNIOR, C. R. B. "Quanta decepção me esperava fora dos limites da nossa casa": geografias afetivas do habitar em Lavoura arcaica, de Raduan Nassar. Geousp - Espaço e Tempo (Online), v. 23, n. 1, p. 076-094, abr. 2019. ISSN 2179-0892.

Disponível em: https://www.revistas.usp.br/geousp/article/ view/144704. doi: https://doi.org/10.11606/issn.2179-0892. geousp.2019.144704.

\section{(c) (1) \& $(9)$}

Este artigo está licenciado sob a Creative Commons Attribution 4.0 License. 


\title{
"Quanta decepção me esperava fora dos limites da nossa casa": geografias afetivas do habitar em Lavoura arcaica, de Raduan Nassar
}

\section{Resumo}

Romance publicado originalmente em 1975, Lavoura Arcaica narra a partida e o retorno do filho do meio de uma família camponesa. No enredo em fluxo de consciência, André, o protagonista, descreve suas experiências, percepções e condições de habitar no âmago do lugar-lavoura. Pelo ordenamento da família, que se divide em função de divergentes formas de conceber as geografias afetivas do lar, conformam-se espacialidades de tensão. Por meio de hermenêutica embasada na fenomenologia existencialista de Merleau-Ponty, o artigo problematiza o modo como se irradiam as contradições do habitar na geograficidade da experiência de André. Pela dinamicidade corpo-espacial, evidencia-se a gênese de uma forma de habitar o lugar em que o emergir do ser-no-mundo é profundamente imbricado por emoções e percepções. Na potencialidade de ser-no-lar, o lugar se redefine contextualmente nos tensionamentos que modificam a forma como é sentida a realidade geográfica. Conclui-se que, pela corporeidade inerente ao entrelaçamento sujeito-lugar, ressaltam-se os fluxos afetivos pelos quais o ser humano projeta sua consciência intencional rumo ao mundo.

Palavras-chave: Geografia e literatura. Lugar. Ser-no-mundo. Corporeidade. Geograficidade.

\section{"How much deception awaited for me outside the boundaries of our home": Affective geographies of dwelling at Ancient Tillage, by Raduan Nassar}

\begin{abstract}
Romance originally published in 1975, "Ancient Tillage" narrates the story of the departure and return of the middle son of a peasant family. At the flux of conscience plot, André, the protagonist, describes his experiences, perceptions and conditions of dwelling at the place-tillage's hearth. Spatialities of tension are emerged by the means of the family order, which is divided by the diverging forms of conceiving the
\end{abstract}


affective geographies of home. This essay problematizes, per the hermeneutics based on Merleau-Ponty's existentialist phenomenology, in which way irradiates the contradictions of dwelling at the geographicity of Andrés experience. It's evidenced that the body-spatial dynamics gives birth to a way of dwelling place in which the emergence of being-in-the-world is profoundly concerned by emotions and perceptions. At the potentiality of being-at-home, the place is contextually redefined by the tensions that modifies how the geographical reality is felt. It is concluded that by the inherently corporeality of the subject-place intertwining intensifies the affective flux by which human beings projects their intentional conscience into the world.

Keywords: Geography and Literature. Place. Being-in-the-world. Corporeality. Geographicity.

\section{Entremeado à semeadura emotiva}

Escrito por Raduan Nassar no final da década de 1960 e publicado inicialmente em 1975 pela editora José Olympio, Lavoura arcaica é uma cicatriz protuberante na literatura brasileira do período. Fugindo do romance panfletário e circunstancial, o autor substancia uma obra em que a escrita densa e poética debate temas filosóficos acerca da dimensão humana da existência. Permeado por metáforas dos cosmos camponês, biblico e da natureza, o livro evoca uma narrativa de relevante efervescência pessoal.

Raduan dimensiona a necessidade de discutir as injustiças que nascem no âmago do próprio ser. Conforme Abati (1999) e Mota (2010), sua obra destrincha o mundo dos relacionamentos, das individuações que são tensionadas pelos moralismos, dessa conflitualidade inerente ao sujeito-grupo. Ao tratar de uma temática que transcende a temporalidade circunscrita, o desvelar das tensões do microcosmo existencial do lar no romance destaca-se pelas entranhas que explicita.

Por meio de fluxo de consciência, a narrativa trata do drama de partida e retorno/ausência e presença de André, filho do meio de uma família campesina. Na narração das reminiscências do protagonista perpassa-se uma dimensão relevante de geograficidade que emana da maneira de habitar e sentir o mundo. Pelos caminhos da sua relação com a lavoura, o protagonista consubstancia vínculos de ancestralidade, natureza, corporeidade e emoção que ressaltam as possibilidades relacionais da existência no lugar.

Essa dimensão de realidade geográfica que se apresenta por meio da relação do sujeito com seu meio oferece trilha fértil para interpretar espacialidades de tensão que residem no cerne do lar. Neste nexo, problematiza-se: de que maneiras as contradições de habitar o lugar emergem na trama de Lavoura Arcaica?

Visa-se explorar as dimensões afetivas e corporais do lugar-lavoura por meio da narrativa do protagonista André. Pelos vínculos e percepções do personagem intenta-se repensar acerca das potencialidades explicativas do conceito de lugar. Nesta empreitada de interpretação das espacialidades diegéticas do romance, recorre-se à fenomenologia existencialista, par- 
ticularmente na perspectiva de Merleau-Ponty $(2011,2012,2014)$. Pelos trilhos do lavrar desse referencial teórico-metodológico, busca-se explorar a narrativa da obra por meio do mundo que se abre nela. Compõe-se, destarte, uma hermenêutica na qual a leitura é efetivada como via de mão dupla, em que o leitor é lido conjuntamente à obra.

No fértil diálogo dessa geografia humanista, ocorreu um exercício de imersão no mundo da Lavoura Arcaica no qual dinamizaram-se as conexões entre as teorias científico-filosóficas e a trama narrativa. Veleja-se no mar aberto pelo cosmo do romance em busca de expandir o leque interpretativo das geograficidades do habitar humano. Como mencionado, por meio da hermenêutica, intenta-se uma geografia como forma ampla de ler e decifrar o mundo.

Essa leitura diferencia-se das abordagens convencionais em Geografia e Literatura pela maneira como há um enfoque no espaço existencial interno da narrativa. Estudos nesse campo, como discorrem Marandola Jr. e Oliveira (2009), usualmente abordaram os romances como fontes documentais para desvelar determinada região, território ou identidade. Na classificação dos autores, a intenção desse artigo situa-se no campo de Geografias simbólicas e criadas. A aproximação, nesse caso, abrange as geograficidades expostas na percepção dos sujeitos-personagens, de modo a compreender sentidos ambivalentes entre imaginação e verossimilhança que podem contribuir para decifrar o conceito de lugar.

Para a emersão deste artigo, se o dividiu em três partes. Na primeira, "Para habitar o lugar: entre as intimidades da cicatriz", identificam-se os fluxos de afetividade e corporeidade do lugar conforme se desvelam no habitar de André. A segunda, "Estéticas do galho esquerdo (a Mãe?)", visa salientar as clivagens do núcleo familiar e suas repercussões no lar. Finalmente, "Intimidades sensórias nas fronteiras do lar" pretende desvelar as condições de ser-no-mundo por meio do microcosmo existencial e perceptivo do lugar de André.

\section{Para habitar o lugar: entre as intimidades da cicatriz}

Como condição primeira para o existir na Terra, conforme delineia Dardel (2011), o habitar sumariza a espacialidade inerente ao ser humano. Contextualiza-se na centralidade da consciência humana que encaminha as maneiras de definir o espaço por meio de atividade intencional racional e emotiva. Nesse fundante imbricamento, gesta-se a maneira de reação ao meio em que a dimensão do ser-no-mundo projeta no cosmo e manifesta um ordenamento intersubjetivo que dota de significação a espacialidade.

É relevante, como pondera Tuan (2012b, p. 162), que "em qualquer lugar onde haja seres humanos haverá o lar de alguém - com todo significado afetivo da palavra". Núcleo concernente do habitar, o lar configura-se como lugar-princípio na rede espacial constituída pelos sujeitos. Pela ordem primordial de sua substancialização, a geografia afetiva que toma forma nessa espacialidade sistematiza vínculos existenciais de um amplo espectro de emoções.

Em Lavoura Arcaica, a maneira pela qual André rememora o peso do ambiente familiar reconstitui significativamente essa vinculação profunda efetivada pelo habitar. Tema central de suas agonias e contradições, o lar evoca no protagonista o percurso imaginário-poético pelos corredores da casa paterna que é o centro da primeira parte do romance, A Partida. Conforme André significa emotivo-intencionalmente as relações manifestas no lar, está a definir o espaço em que configura o lugar. 
É neste nexo que a lavoura é particularmente relevante na narrativa introspectiva do personagem. Ao realizar sua jornada pelas memórias de habitar, delineia perceptivamente os sentidos emocionais que diferenciam o mundo doméstico daquele que se encontra fora dele. Essa situação encarrega-se de demonstrar o processo de enraizamento em sua realidade geográfica. De acordo com Tuan (1982, p. 52, tradução nossa):

Para tornar-se mundo e lar para o "eu", o espaço deve ser definido. Todos os seres humanos fazem algum esforço consciente para definir o espaço, mas não necessariamente por meio da construção de uma casa material. $\bigcirc$ que uma casa material faz de maneira fantástica é fazer com que o caráter de um mundo humano se apresente vividamente presente aos sentidos e à mente. Um espaço fechado contém, concentra e dá foco à psique humana. ${ }^{1}$

Entre as porteiras que cercam a lavoura, coexistem elementos que vivificam um mundo de campesinidades ditadas pela ordem paterna. As edificações do lar apresentam aos sentidos e espíritos dos habitantes as lógicas e processos decorrentes do modo de habitar. É efetiva a virulência do sermão do Pai ao pregar que "estando a casa de pé, cada um de nós estaria também de pé, e que para manter a casa erguida era preciso fortalecer o sentimento do dever, venerando os nossos laços de sangue, não nos afastando da nossa porta, respondendo ao pai quando ele perguntasse" (Nassar, 1989, p. 21). Esse dever imposto pelo trabalho, pela honra e pelo respeito ao status quo encaminha a definição do lar na lavoura.

$\bigcirc$ Pai centraliza a edificação do lar pelo modo em que constitui entidade que forma o cerne da dinâmica existencial de lavrar o habitar. Contextualmente, há uma relação fundante entre o refreamento das vontades e a submissão ao dever que compõe também a virulência que ergue a casa. Estabelece que a relação lar-Pai-afetividade gesta vínculos ativos da força dos laços de sangue que assombra as paredes do lar. Essas trilhas ordenadoras do mundo constituem processo ativo do habitar.

Para consubstanciação de seu existir, como propõe Tuan (1982; 1995; 2012a; 2012b), é necessário um embasamento ao mundo humano. Ao expandir a lógica desse microcosmo, a lavoura, na condição de lugar com dimensões i-materiais, transcende-se na vivência do protagonista. Ainda que com seus caracteres coercitivos, projeta condições de caráter fundante da ontogênese de seu habitar. Pela densidade simbólico-afetiva nele materializada, o lugar é evocado entremeado ao amplo espectro de emoções ambivalentes de André, que relembra:

[... era boa a luz doméstica da nossa infância, o pão caseiro sobre a mesa, o café com leite e a manteigueira, essa claridade luminosa da nossa casa e que parecia sempre mais clara quando a gente vinha de volta lá da vila, essa claridade que mais tarde passou a me perturbar, me pondo estranho e mudo, me prostrando desde a puberdade na cama como um convalescente, "essas coisas nunca suspeitadas nos limites da nossa casa” eu quase deixei escapar, mas ainda uma vez achei que teria sido inútil dizer qualquer coisa, na verdade eu me sentia incapaz de dizer fosse o que fosse (Nassar, 1989, p. 26).

\footnotetext{
"Space, to become a world and a home for self, must be defined. All human beings make some conscious effort to define space, though not necessarily by constructing a material house. What a material house does supremely well is to make the character of the human world vividly present to the senses and to the mind. An enclosed space contains, concentrates, and focuses the human psyche" (Tuan, 1982, p. 52).
} 
Imbrica-se, na perspectiva de André, um sentir que perpassa seu corpo ao retornar imaginativamente à casa de infância. Os cheiros e luminosidade dos tempos de infante anunciam uma relação vinculativa com a aparente segurança oferecida pelo lar. Em contraponto à vila, era uma claridade harmoniosa, dotada dos afetos da Mãe. Ao mesmo tempo, expõe a visceral força da angústia que o tomou a partir da puberdade. $\bigcirc$ lugar, embora mantido em mesma realidade geográfica, transmuta por meio da perspectiva corpo-espacial que transforma em função dos desejos reprimidos.

A inutilidade de revelar seus insuspeitáveis suspiros ao primogênito Pedro demonstra o poder viril do silêncio paterno que volta a assolá-lo. Se, como afirma Relph (1976, p. 39, tradução nossa), "lar é a fundação de nossa identidade como indivíduos e membros de uma comunidade, a moradia-lugar do ser", ${ }^{2}$ na lavoura, manifesta-se na violência da submissão à vontade do patriarca. Essa situação ressalta a preterição da individualidade em favor do trabalho coletivo na lavra.

sentido de lugar no habitar de André emerge no entorno de suas condições de ser-no-mundo. Ele decorre das contraposições expostas pelas diferentes formas de sentir o lar que está contido nessa ambivalência entre a opressão e individuação. Sua afetividade conecta o mundo e a percepção no cosmo do lugar como forma de compor expressão intersubjetiva da realidade geográfica na qual se insere.

É oportuno salientar, conforme Seamon e Mugerauer (1985, p. 8), que "habitar envolve o processo pelo qual um lugar em que existimos se transforma em um mundo pessoal e lar". 3 Mesmo que o cosmo estabelecido esteja dotado de elementos que indicam a violência viril do patriarca, é nesse mesmo lugar que coexiste a intimidade pueril do protagonista. André enseja, nesse processo, o emergir de outra forma de habitar, pautada na radicalização da afetividade materna do lado esquerdo do tronco familiar. Como desnuda as relações domésticas:

Eram esses os nossos lugares à mesa na hora das refeições, ou na hora dos sermões: o pai à cabeceira; à sua direita, por ordem de idade, vinha primeiro Pedro, seguido de Rosa, Zuleika, e Huda; à sua esquerda, vinha a mãe, em seguida eu, Ana, e Lula, o caçula. $\bigcirc$ galho da direita era um desenvolvimento espontâneo do tronco, desde as raízes; já o da esquerda trazia o estigma de uma cicatriz, como se a mãe, que era por onde começava o segundo galho, fosse uma anomalia, uma protuberância mórbida, um enxerto junto ao tronco talvez funesto, pela carga de afeto; podia-se quem sabe dizer que a distribuição dos lugares na mesa (eram caprichos do tempo) definia as duas linhas da família (Nassar, 1989, p. 154-155).

A observação da disposição da família relaciona-os ao cerne de ser-no-mundo de sua realidade geográfica no lar. Efetivam-se dois centros perceptivos que clivam o lugar. $\bigcirc$ sujeito-moral família, manifesto na mesa, delineia uma estética espacial que ressalta a cicatriz do tronco da lavoura. Da mesma raiz de que vigora o galho direito, o enxerto funesto do esquerdo permanece como ente definidor de tensões domésticas. Evidencia-se que na percepção de André há uma corporeidade inerente na forma como os sujeitos concretizam seus lugares.

2 "Home is the foundation of our identity as individuals and as members of a community, the dwelling-place of being" (Relph, 1976, p. 39).

3 "Dwelling involves the process by which a place in which we exist becomes a personal world and home" (Seamon; Mugerauer, 1985, p. 8). 
Arquitetam-se caminhos de opressão e resistência que são esculpidos por diferentes lógicas de vivência e estética corpo-espacial. Como ressalta Merleau-Ponty (2011, p. 384), "nosso corpo e nossa percepção sempre nos solicitam a considerar como centro do mundo a paisagem que eles nos oferecem. Mas esta paisagem não é necessariamente aquela de nossa vida". O campo perceptivo que separa as vertentes do lar é a realidade geográfica da qual partem ambas maneiras de definir o lugar. Esse centro do mundo de que se irradiam diferentes geografias afetivas ressalta as divergentes formas de compreensão do lar.

No sentido de que o ventre materno germina um nascer que implica a revolta contra o patriarca autárquico, referencia-se no tronco originário como ponto primeiro à transgressão. Larsen e Johnson (2012, p. 642, tradução nossa) sintetizam: "Em suma, a afinidade está em toda parte e em todo lugar corporificado - descentralizado, rizomático, anárquico", ${ }^{4}$ de modo que sua espacialidade é sintomática da oposição à linearidade impositiva do cosmo. Analogamente, pode-se entender que o afeto entre os personagens do galho esquerdo é sua arma de irreverência frente ao habitar imposto pelo Pai.

O lar transfigura-se pela cisão-cicatriz que emerge da divisão entre as linhas familiares. Decorrente de um apropriar que fundamenta o lar, a estética materna centrada no corpo e no passional reúne insatisfação com a ordem paterna imposta ao lugar. Considera-se que, na perspectiva de Seamon (1979, p. 80, tradução nossa):

O lar apropria espaço. A apropriação envolve, primeiro, um sentido de posse e controle: a pessoa que está em casa toma o espaço do qual está encarregada. A apropriação é interrompida quando o lar é infringido de alguma maneira; o sujeito-sentir reage imediatamente. ${ }^{5}$

Este nexo torna explícito que a afetividade é um processo de apropriação espacial que instaura certa medida de controle sobre a cosmografia do lugar. $\bigcirc$ irromper de revolta do lado esquerdo implica em uma vontade de apropriar-se que infringe o controle do patriarca, ou seja, em vontade de desafiar sua lógica. Nesse sentido, a fuga de André, como sumarização dessa irreverência, gera uma resposta no sujeito-sentir do patriarca. Essa é manifesta no envio de Pedro, continuidade de sua vontade, ao quarto de pensão para "resgatar" o irmão pródigo.

\section{Estéticas do galho esquerdo (a Mãe?)}

No contexto do habitar, a gestalt firma-se pela dinâmica de apropriações conflituosas no âmago do lugar familiar. Se na estética do lar o galho direito parece firme, extenso e vívido, o da esquerda é uma ruptura de infertilidade que incide de certa eroticidade materna. Na experiência de André esse elemento também decorre no incesto com sua irmã Ana.

4 "Affinity, in short, is everywhere and everywhere embodied - decentralized, rhizomatic, anarchic" (Larsen; Johnson, 2012, p. 642).

5 "The home appropriates space. Appropriation involves, first, a sense of possession and control: the person who is at home holds a space over which he is in charge. Appropriation is disturbed when a home is infringed upon in some way; feeling-subject immediately reacts (Seamon, 1979, p. 80). 
No sentido de que "a condição estética do lar também pode ser suspeita porque não é conspicuamente visual"'6 (Tuan, 1995, p. 113, tradução nossa), pondera-se que a virtualidade emotiva rege a gestalt do habitar. Nos caminhos das geografias afetivas da lavoura, é evidente a potência destrutiva e criativa do fazer-lugar matriarcal. Sua estética afetiva contrapõe o refreamento passional patriarcal.

Contudo, ao chafurdar e ironizar os nexos de apropriação paterna, André emerge na condição de indivíduo ativo que estabelece sua própria estética. Tomando por princípio, como Hoyaux (2003, p. 6, tradução nossa), que "esse projeto de existência, de aparecimento no mundo, não releva a necessidade do ser de se cercar do espaço doméstico, mas a necessidade de circundar um mundo que é o doméstico", 7 desvela-se que o sentir de André é dotado de contornos domésticos que afloram afetividades latentes ao lar.

Na inexorabilidade do mundo doméstico, como pondera o autor (Hoyaux, 2003), a experiência transcendente de circundar-se nesse cosmo emana como forma de intencionalidade corpo-sujeito. Pela composição da revolta de André, a proximidade estético-afetiva do galho esquerdo projeta uma ruptura que é sistematizada na experiência de seu retorno:

[...] minha cabeça foi de repente tomada pelas mãos da mãe, que se encontrava já então atrás da minha cadeira; me entreguei feito menino à pressão daqueles dedos grossos que me apertavam uma das faces contra o repouso antigo do seu seio; curvando-se, ela amassou depois seus olhos, o nariz e a boca, enquanto cheirava ruidosamente meus cabelos, espalhando ali, em língua estranha, as palavras ternas com que sempre me brindara desde criança: "meus olhos" "meu coração" "meu cordeiro" (Nassar, 1989, p. 169-170).

No encontro perpassado no seio fundador do galho esquerdo, André rememora os lugares de sua infância. Sente, nos dedos grossos da camponesa, as sementes de sua inquietude. No corpo em que o lugar se faz sensível, faces do passado são evocadas. Como afirma Pile (2010, p. 11, tradução nossa), "o corpo é um sítio de sentimento e experiência. Esses experiências e sentimentos são embutidos socialmente, mas eles são localizáveis no corpo e nas relações entre corpos". ${ }^{8}$ É nesse calor humano, de um cheirar ruidoso, que se manifesta o encontro de perspectivas espaciais do cerne do lar.

Entre essas geografias emocionais, faz-se presente a experiência geográfica de corpos-sujeitos que se conformam em um espaço que fazem lugar pela significação relacional estabelecida. Se "espaço vivido é enraizado em, e não pode ser entendido fora do corpo vivido"9 (Carr, 2004, p. 3, tradução nossa), infere-se que existe conectividade entre as mãos calejadas e os corpos cansados das incertezas dos ciclos da lavoura. Esses sentimentos afetivos são inseparáveis de sua corporeidade e dimensionam a maneira pela qual a espacialidade do reencontro se desdobra na tangibilidade do espaço onde habitam.

6 "The aesthetic standing of the home may also be suspect because it is not conspicuously visual" (Tuan, 1995, p. 113).

7 "Ce projet d'existence, dès l'apparaitre au monde, relève non pas du besoin d'être entouré par un espace domestique mais de la nécessité de s'entourer d'un monde que l'on domestique" (Hoyaux, 2003, p. 6, tradução nossa).

8 "The body is a site of feeling and experience. These experiences and feelings are socially embedded, but they are localizable in the body, and relationships between bodies" (Pile, 2010, p. 11).

9 "Lived space is rooted in, and cannot be understood apart from, the lived body" (Carr, 2004, p. 3). 
Decorre, como propõe Morris (2004, p. 119, grifo do original, tradução nossa), que "nosso corpo é de espaço, não apenas jogado nele como em um contêiner. Por quê? Porque ele se move, e a gramática profunda do movimento corporal gera um envelope interno de percepção que já detém um sentido espacial". ${ }^{10}$ Essa dinamicidade corpo-perceptiva indica o senso direcional da continuidade do espaço onde se origina um ventre de poiésis e revolta.

Conforme define Dardel (2011, p. 1-2), "uma relação concreta liga o homem à Terra, uma geograficidade (geógraficité) do homem como modo de sua existência e de seu destino", identifica-se que o trato afetivo realizado entre a Mãe e o cordeiro ressalta a conexão fundante entre a lavoura-lugar e os sujeitos. Na composição cenográfica a intercorporeidade retoma as condições de ser-no-mundo originárias do tronco fundador e estabelece um novo sentido como forma de ser.

Nessa profundidade sensória do mover-se, a corporeidade do contato gera uma repercussão que transborda a geograficidade como propelente do modo de viver o lugar. Para Hummon (1992, p. 262, tradução nossa), "a natureza do sentido de lugar é inevitavelmente dual, envolvendo tanto uma perspectiva interpretativa do ambiente quanto uma reação emocional ao ambiente". "Na consubstancialização do lugar, há a necessidade de uma troca recíproca em que corpo-lugar se projetam por meio de nexos emocionais que fundem entremeio à realidade geográfica disposta.

Essa afetividade entre Mãe e André é essência fundante do modo de ser no lugar para ambos. Ao fugir da lavoura, o protagonista descentraliza elementos e perspectivas do cosmo do lar e os suprime durante a estadia na vila. A dinamogenia do contato entre os mundos que ressalta o sentido de lugar por meio da relação emotiva é particularmente relevante na forma como Pedro transpõe a lavoura ao quarto de pensão. Diz o primogênito:

[... ela não contou pra ninguém da tua partida; naquele dia, na hora do almoço, cada um de nós sentiu mais que o outro, na mesa, o peso da tua cadeira vazia; mas ficamos quietos e de olhos baixos, a mãe fazendo os nossos pratos, nenhum de nós ousando perguntar pelo teu paradeiro (Nassar, 1989, p. 23).

Se, como propõe Tuan (2013, p. 167), "o espaço transforma-se em lugar à medida que adquire definição e significado", é nesse caso a falta de André na mesa que sintomatiza uma forma de redefinição no lugar. Como perspectiva interpretativa e emocional de geograficidade, o sentido de lugar manifesto na cadeira vazia é um desordenamento do topos do patriarca.

$\bigcirc$ desconforto que reverbera pela mesa, nos olhos baixos e quietos dos irmãos, conflui no rompimento de uma lógica tópica que centrava as tradições na figura da permanência do lar. Tem peso e dimensão a cadeira que expressa a falta do filho do meio. A dor da mãe reverbera em cada pedaço da mobilia da casa de modo que não seja necessário ou permitido perguntar o que ocorreu.

É também o lugar que sente a falta de André, ecoando os sentidos projetivos nele manifestos pelos corpos-sujeitos que o habitam. Dessa geograficidade do vazio à mesa projeta-se a alteração da experiência de lugar para aqueles que permanecem no lar. A realidade geográfica,

10 "Our body is of space, not just dropped into it as into a container. Why? Because it moves, and the deep grammar of bodily movement generates an inner envelope of perception that already has a spatial sens" (Morris, 2004, p. 119, grifo do original).

11 "Sense of place is inevitably dual in nature, involving both an interpretative perspective on the environment and an emotional reaction to the environment" (Hummon, 1992, p. 262). 
como aponta Dardel (2011), não é um todo indiferente, mas potencialidade explorada pelo ser-no-mundo que interfere ao expressar sua existência. No campo simbólico traçado pelas formas de viver a lavoura, a ausência é uma externalização da angústia e revolta do protagonista.

O habitar, definidor de potencialidades afetivas no lugar por meio do corpo, transcende-se pela inexorabilidade de sua intersubjetividade. Como desdobramento de realidade geográfica, é manifesto pela inseparabilidade ontogênica do mundo conforme projetado pelos sujeitos. São os somatórios das estéticas das vertentes divergentes do lar que dinamizam o lugar, primordialmente na imposição dos nexos do galho direito centrado no sentimento de dever.

A angústia, como elemento que parte dessa imposição, motiva a ação transformadora do lar manifesta no incesto André-Ana e na fuga do protagonista. De acordo com Morris (2004, p. 158, grifo do original, tradução nossa) "nosso sentido de espaço se refere ao movimento corpo-mundo, a um esquema móvel de percepção". ${ }^{2}$ "Nesse sentido, mudanças na fluidez do cotidiano afetam o sentido da espacialidade do mundo. $\bigcirc$ esquema do movimento corpo-mundo da partida de André desfigura a raiz do trabalho-lavrar, sinal de honra e pedra fundamental do discurso paterno.

Se, como pensa Seamon (2008, p. 5, tradução nossa), "qualidades de habitantes sustentam qualidades da casa, que, em retorno, sustenta qualidades dos habitantes", 13 é na inexorabilidade de ser-no-lar que o lugar se projeta como forma de devir do mundo habitado. Conforma-se uma ciclicidade de reversibilidade lar-habitante que é realçada nas diferentes vivências de transgressão e segurança da ordem paterna na lavoura.

Contextualiza-se que ser-no-lar constitui nexo de experiências em que o habitar é projetado na direção de significação do mundo em cosmo. Particularmente, a maneira de enxertar na mesa de sermões pela afetividade é uma proposta irreverente de outro sentido para o fazer-lugar. Reposiciona o mundo vivido de modo a propor outro pano de fundo para a realidade geográfica. Para além da coerção autárquica paterna, André desvela no incesto com Ana que:

[...] a mãe não gerou só os filhos quando povoou a casa, fomos embebidos no mais fino caldo dos nossos pomares, enrolados em mel transparente de abelhas verdadeiras, e, entre tantos aromas esfregados em nossas peles, fomos entorpecidos pelo mazar suave das laranjeiras; que culpa temos nós dessa planta da infância, de sua sedução, de seu viço e constância? que culpa temos nós se fomos duramente atingidos pelo vírus fatal dos afagos desmedidos? que culpa temos nós se tantas folhas tenras escondiam a haste mórbida desta rama? que culpa temos nós se fomos acertados para cair na trama desta armadilha? (Nassar, 1989, p. 129).

Nas vias do corpo-habitar, o lugar conflui com os contextos relacionais evocados pela realidade geográfica. A revolta maternal objetiva a gênese de um outro ser-no-lar que virtualize um equilibrio entre afetividade e refreamento. Porém, ela também é semente de excessos passionais, da virulência de afagos desmedidos. André decifra o mel da infância como transgressão por meio de envolvimento corporificado que conflui no viço mórbido do contato entre suas ramas.

12 "Our sens of space refers to body-world movement, to a moving schema of perception" (Morris, 2004, p. 158, grifo do original).

13 "Qualities of inhabitants sustain qualities of house, which in turn sustain qualities of inhabitants" (Seamon, 2008, p. 5). 
Pelo ato sexual irreversível, não há como recriar efetivamente a ordem do lugar patriarcal. Ao remeter os discursos paternos à irmã, André os perverte por meio do nexo matriarcal. Arquiteta uma versão própria dos fatos em que é salutar a ausência de verdade que instaura transgressividade motriz de uma atitude limítrofe no seio do lar. A radicalização fruto dessa ação é presságio da tragédia que virá a se instalar em sua páscoa.

Em termos gerais, seu conflito decorre do que escreve Tuan (2012a, p. 146): "Na Terra, somos expostos às forças brutais da natureza e da sociedade, das quais ninguém - e certamente não os bons - pode se proteger. Também sofremos por ser agentes que atuam no mundo, e isso necessariamente significa superar algum tipo de barreira". ${ }^{14} \mathrm{Na}$ situacionalidade de ser-no-mundo, a afetividade que é purgada pela realidade geográfica dos domínios do Pai apresenta-se como percurso inicial da revolta.

Pela perspectiva de que a emoção é transformadora da expressão do lugar, o contato corpo-sexual do ato incestuoso é redefinidor da ordem pela dessacralização da geograficidade do patriarca. Como ressalta Casey (1998, p. 236, tradução nossa), na perspectiva de Merleau-Ponty, "o corpo é ele mesmo produtivo-de-lugar, concretizando lugares por meio de seus movimentos expressivos e orientacionais, seu literal dinamismo cinético". ${ }^{15} \bigcirc$ corpo-sujeito, destarte, (re)cria lugares que habita pela lógica da projetividade perceptiva que direciona os sentidos de espacialidade.

É nessa lógica de habitar que mundo, lar e sujeito se inserem no nexo de reversibilidade cinética que proporciona a dinâmica corporificada de lugar. Na orientação irreverente da substancialização desse modo de ser-no-lar, a atitude incestuosa e a partida se somam como propostas de criação do lugar sob a realidade geográfica da lavra.

\section{Intimidades sensórias nas fronteiras do lar}

$\bigcirc$ mundo que o sujeito projeta pela experiência sensorial corresponde aos microcosmos existenciais que percorrem a lógica de constituição da realidade geográfica. Pela corporeidade substanciada na geograficidade, os componentes do lugar emergem na arquitetura da percepção que possibilita o habitar. Na posição intersubjetiva do vir a ser, a transcendência da espacialidade se faz pela projetividade inerente à dinamogenia da razão de ser-no-mundo.

É tomado como princípio, tal qual escreve Merleau-Ponty (2011, p. 576), que "o mundo é inseparável do sujeito, mas de um sujeito que não é senão projeto do mundo, e o sujeito é inseparável do mundo, mas de um mundo que ele mesmo projeta”. Os cosmos expandidos na lavoura apresentam nexos íntimos que indicam experiências de reversibilidade no âmago do lar. $\bigcirc$ mundo expandido pela experiência intersubjetiva da lavoura se conecta à corpo-consciência e é substrato por onde fluem as intencionalidades.

Esse processo indica que a reversibilidade mundo-sujeito aprofunda-se por meio da corporeidade e provoca reatividades em nível da intersubjetividade inexorável à percepção. Como ressalta Merleau-Ponty (2014, p. 22), "nós vemos verdadeiramente a coisa mesma e a mesma

14 "On Earth we are exposed to the brute forces of nature and society, which no one - and certainly not the good - can avoid. We also suffer from being agents who act on the world, and that necessarily means overcoming some sort of barrier" (Tuan, 2012a, p. 146).

15 "The body itself is place-productive, bringing forth places from its expressive and orientational movements, its literally Kinect dynamism" (Casey, 1998, p. 236). 
coisa - e, ao mesmo tempo, não alcanço nunca a vivência de outrem. É no mundo que nos reunimos". Há, portanto, uma constante reação entre sujeito e grupo que se projeta pelo mundo intersubjetivo do lar. Se André sofre com a situação que é experienciada, a família é implícita a esse sofrer.

Abati (1999, p. 103) comenta que, na lavoura, a "troca intersubjetiva se encarregou de embaralhar as esferas individuais, constituindo a visão-de-mundo que norteia o protagonista, fragmentada em duplos que se embatem". Evidencia-se que o ambiente familiar alicerçado pela dinâmica do embate provocando a cisão do tronco ressalta em André uma cicatriz que torna seus sentimentos em contradições densas. Ao mesmo tempo em que o protagonista expressa uníssono nexo experiencial à lavoura, é tomado pela virulência irreverente.

Emoção e percepção, na condição de nodos para o emergir do lugar, indicam condições de consciência e intencionalidade que conjuntas encaminham a realidade geográfica. Ao mesmo tempo em que é afetado por essa geograficidade originária, André consegue estabelecer vínculos e elos substancializados em sua forma de ser. Segundo Davidson e Milligan (2004, p. 524, tradução nossa), "[...] nossas emoções importam. Elas têm efeitos tangíveis em nosso entorno e podem moldar a própria natureza e experiência de ser-no-mundo. Emoções podem claramente alterar o modo pelo qual o mundo é para nós, afetando nosso senso de tempo assim como de espaço". ${ }^{16}$ Logo, são esses elementos emotivos, corpo-perceptivos, que se misturam e formam alquimias de direções para o sentido de lugar.

O corpo sensível/perceptível e o ser-no-mundo em André compõem-se como maneira de existir em que a afetividade se dinamiza no nexo de seu lugar. Ao dimensionar a centralidade de enxergar os utensílios domésticos, encaminha o modo pelo qual o mundo é alterado pelas emoções que confluem no seio da lavoura. $\bigcirc$ sujeito, permeado pela realidade geográfica, rememora o núcleo do habitar que permanece em sua forma de sentir.

André está experiencialmente sujeitado ao lugar onde principia sua existência, visto que opera como mundo-gênese; fato que guia sua maneira de sentir e expressar o mundo. Essa conexão primal não se manifesta em proximidade incondicional à lavoura. Ao mesmo tempo em que se vê entremeado das raízes do lar, mantém um desejo latente de fuga. Para Relph (1976, p. 42, tradução nossa) "nossa experiência de lugar, e especialmente de lar, é uma dialética contrabalanceia uma necessidade de permanência com o desejo de escapar". ${ }^{17}$

As vivências de transgressão e segurança, realçadas por uma certa ciclicidade dos galhos do tronco familiar, despertam sentimentos contraditórios na relação com o lugar. Da mesma forma que a ponderação anterior de Relph (1976), o pretenso equilibrio que se conforma na situação impele André a agir. Na indissociabilidade efetivada em mundo-sujeito, a experiência que orienta a realidade geográfica adquire concretude na descrição de André de sua partida:

[...] que poeira clara, vendo então as costas daquele tempo decorrido, o mesmo tempo que eu um dia, os pés acorrentados, abaixava os olhos para não ver-lhe a cara; e que peso o dessa mochila presa nos meus ombros quando saí de casa;

16 "[...] our emotions matter. They have tangible effects on our surroundings and can shape the very nature and experience of our being-in-the-world. Emotions can clearly alter the way the world is for us, affecting our sense of time as well as space" (Davidson; Milligan, 2004, p. 524).

17 "Our experience of place, and especially of home, is a dialectical one - balancing a need to stay with a desire to escape" (Relph, 1976, p. 42). 
colada no meu dorso, caminhamos como gêmeos com as mesmas costas, as gemas de um mesmo ovo, com olhos voltados pra frente e olhos voltados pra trás (Nassar, 1989, p. 32).

É na fuga que sente o mundo somado às suas costas. Como um Atlas, carrega corporalmente o lugar, essa gema de um mesmo ovo que cola em seu dorso. A poeira clara que permeia o tempo a decorrer espacializa as emoções da partida, dotada de uma angústia pela incapacidade de se desvencilhar do cosmo da lavoura. A contradição na situação de habitar condiz com seus pés que, acorrentados, permanecem a puxá-lo de volta para casa.

Mundos e emoções compelem-se na trajetória da partida e retorno de André. Ocorre que cada partícula de sentido posta revela a realidade geográfica e o sujeito projetivo da geograficidade presente. Nessa estética de poiésis da terra, evoca-se que a dinâmica perceptiva é um elemento que potencializa a metamorfose das condições de existência de sujeito e lugar.

Em perspectiva merleau-pontiana, Morris (2004, p. 66, tradução nossa) afirma: "a percepção não é um evento fechado em torno de quem percebe, ela se manifesta em um circuito móvel entre quem percebe e o mundo". ${ }^{18} \bigcirc$ lugar propele a percepção por configurar-se como fenômeno que vivifica a situação existencial. $\bigcirc$ mundo doméstico do circuito perceptivo de André é composto por uma cenografia em que as coisas são apresentadas como extensões do corpo familiar. É revelador ao desvelar que:

Fundindo os vidros e os metais da minha córnea, e atirando um punhado de areia pra cegar a atmosfera, incursiono às vezes num sono já dormido, enxergando através daquele filtro fosco um pó rudimentar, uma pedra de moenda, um pilão, um socador provecto, e uns varais extensos, e umas gamelas ulceradas, carcomidas, de tanto esforço em suas lidas, e uma caneca amassada, e uma moringa sempre à sombra machucada na sua bica, e um torrador de café, cilíndrico, fumacento, enegrecido, lamentoso, pachorrento, girando ainda à manivela na memória; e vou extraindo deste poço as panelas de barro, e uma cumbuca no parapeito fazendo de saleiro, e um latão de leite sempre assíduo na soleira, e um ferro de passar saindo ao vento pra recuperar a sua febre, e um bule de ágata, e um fogão a lenha, e um tacho imenso, e uma chaleira de ferro, soturna, chocando dia e noite sobre a chapa; e poderia retirar do mesmo saco um couro de cabrito ao pé da cama, e uma louça ingênua adornando a sala, e uma Santa Ceia na parede, e as capas brancas escondendo o encosto das cadeiras de palhinha, e um cabide de chapéu feito de curvas, e um antigo porta-retrato, e uma fotografia castanha, nupcial, trazendo como fundo um cenário irreal, e puxaria ainda muitos outros fragmentos, miúdos, poderosos, que conservo no mesmo fosso como guardião zeloso das coisas da família (Nassar, 1989, p. 62-63).

Entre o percebido e o sujeito, é gestado um elo complexo em que a mundanidade da dinâmica de lugar arquiteta características pelas quais o sujeito se projeta nos objetos. Se, como pensam Larsen e Johnson (2012, p. 641, tradução nossa), "cognição, existência e, de fato, todas

18 "Perception is not an event enclosed within the perceiver, it is manifest in a moving circuit between the perceiver and the world" (Morris, 2004, p. 66). 
as coisas presentes originalmente dependem do lugar como um acontecimento situado mas universal, ou revelação requerida pelo mundo - natural e humano - para se manifestar. Lugar faz mais que abrir caminho; ele embasa", ${ }^{19}$ é possível inferir que a percepção de André como elemento embasado na lavoura também é baluarte da experiência do fenômeno indiviso de lugar.

Cada objeto repercute os substantivos gemidos e corporeidades dos sujeitos circunscritos às fronteiras do ordenamento patriarcal. $\bigcirc$ ato perceptivo transmuta o lar e as coisas ao personalizá-las por meio da humanização de suas características. As gamelas estão ulceradas, ressaltam as marcas das aflições cotidianas. Merleau-Ponty (2012, p. 112) considera que a percepção "afeta todos os elementos de um corpo ou de uma conduta, de um certo desvio comum em relação a uma norma familiar que possuo em meu íntimo". As coisas percebidas se misturam com quem as percebe de forma que é impossível distinguir como um habita o outro.

Ao girar a manivela da memória, torrador de café necessita de alguém que o coloque em movimento. A louça que adorna a sala, a dividir espaço com a Santa Ceia, implica certa ingenuidade que aparenta se referir à pretensa crença na união nos domínios das porteiras do Pai. $\bigcirc$ saleiro e o pilão, a moringa, tudo se interpenetra pela mente consciente do protagonista que os sente. A percepção reelabora a continuidade corpo-lugar que gesta novos mundos íntimos, em um devir perceptivo que metamorfoseia a realidade geográfica.

André recorda cada coisa porque todas elas emergem como partes significantes do lugar. Na concepção de Murchadha (2015, p. 35, tradução nossa) "Todas as coisas acontecem, estão no lugar, e o lugar é aquilo que as faz possíveis na condição de coisas". ${ }^{20}$ Se não fossem componentes fundantes do lugar não haveria sentido ou conexão para as coisas descritas como emergem ao mundo. Pela percepção as coisas vivem, pulsam e planam pelas geografias afetivas dos sujeitos que as habitam.

Como verdadeiros mundos de experiência, as coisas abrem-se no horizonte do sujeito. Quão revelador é o poço de que extraí as panelas de barro, o tacho, o leite - assíduo - na soleira? Todos esses elementos que comportam a mesma cozinha na qual fica o fogão a lenha capturam em um só momento, em flash perceptivo, a espacialidade densa de intencionalidades. Cada uma dessas coisas transcende a dimensão de parte e define a lavoura que André sente.

Merleau-Ponty (2011, p. 429) discorre que "toda percepção é uma comunicação ou uma comunhão, a retomada ou o acabamento, por nós, de uma intenção alheia ou, inversamente, a realização, no exterior, de nossas potências perceptivas é como um acasalamento de nosso corpo com as coisas". Essa comunhão perceptiva é uma forma de fazer-lugar por meio do ato intencional de extensão da consciência que se projeta como transformativa no mundo.

Os fragmentos entrecruzados na comunhão perceptiva desvelam uma cartografia do imaginário que emerge no núcleo da relação sujeito-lugar. Define Relph (1976, p. 141, tradução nossa) que "lugares são fusões de ordem humana e natural e são centros significantes de nossas experiências imediatas do mundo". ${ }^{21}$ Nas espacialidades efervescentes que nascem dessa fusão, o corpo fertiliza os sentidos onde a experiência de realidade geográfica é substanciada.

19 "[...] cognition, existence, and, indeed, all things present first depend on place as the situated but universal happening, or disclosure, required for the world - natural and human - to appear. Place does more than bridge; it grounds" (Larsen; Johnson, 2012, p. 641).

20 "All things take place, are in place, and place is that which makes them possible as things" (Murchadha, 2015, p. 35).

21 "Places are fusions of human and natural order and are the significant centres of our immediate experiences of the world" (Relph, 1976, p. 141). 
Porquanto, como propõe Merleau-Ponty (2011, p. 576), "o sujeito é ser-no-mundo, e o mundo permanece 'subjetivo', já que sua textura e suas articulações são desenhadas pelo movimento de transcendência do sujeito", há uma lógica inerente de continuidade do devir em que se projeta o existir. Ao mesmo tempo em que André é fruto do lugar, decifra implicitamente que o lugar também é extensão de sua intencionalidade.

É neste sentido que se configura como sujeito ativo que se faz nas fissuras das imposições do cosmo patriarcal. Se, como destaca Hufford (1992, p. 232, tradução nossa), "lugares não existem fora da experiência ou da compreensão humanas; são sempre lugares-para" ${ }^{22}$ e necessariamente transbordam em falas, atos e gestos dos sujeitos. Como lugar-para aqueles que habitam, a lavoura é arquitetada nessa inerente tensão entre o individual e o coletivo.

Segundo a concepção de que, "fenomenologicamente, lugar não é o ambiente físico separado das pessoas associadas a ele, mas, em verdade, o indivisível, normalmente não percebido fenômeno de pessoa-ou-pessoas-experienciando-lugar" 23 (Seamon, 2014, p. 11, tradução nossa), respalda-se que, mesmo com a saída do sujeito, não se desfaz o sentido de lugar. Em verdade, a redefinição do centro atitudinal cria outra percepção. Centrado em imaginário, memória ou vínculo, o lugar tem a potencialidade de transgredir as vias da materialidade e se tornar espécie de núcleo ideal. Como confessa André:

[... "entenda, Pedro, com meus olhos sempre noturnos, eu, o filho arredio, provocando as suspeitas e os temores na família inteira, não era com estradas que eu sonhava, jamais me passava pela cabeça abandonar a casa, jamais tinha pensado antes correr longas distâncias em busca de festas prós meus sentidos; entenda, Pedro, eu já sabia desde a mais tenra puberdade quanta decepção me esperava fora dos limites da nossa casa" eu disse quase afogado nessa certeza (Nassar, 1989, p. 67).

Ainda na partida, o lugar permanece como ponto de referência em relação ao mundo. A casa permanece como seu centro de significado e ordem porque determina o topos dimensionador de sua definição ao universo de indefinições. No desabafo, André estabelece o mundo vivido em que embasa seus sentidos de lugar. Nessa relação de inseparabilidade, a percepção nutrida pelos olhos noturnos lastreia o âmbito da intersubjetividade da realidade geográfica.

Como ponderam Brown e Perkins (1992, p. 282, tradução nossa), "lugares são experienciados como uma extensão do eu". ${ }^{24}$ Na condição de fenômeno experiencial, André vive a lavoura-lugar como continuidade e parte integral de quem é. Isso efetivamente significa incluir a opressão angustiante e seu processo de individuação como parte integral do corpo-lugar. A confissão acena para o fato de que sua partida é, indiretamente, um movimento que visa um retorno a si.

Como extensão da constituição de André, a lavoura é mais que um espaço de onde ele pode fugir. Isso remete a afirmação de Relph (1976, p. 39, tradução nossa): "lar não é apenas a casa em que acontece você habitar, não é algo que pode estar em algum lugar, que pode ser

22 "Places do not exist apart from human experience and understandings; they are always places-for" (Hufford, 1992, p. 232).

23 "Phenomenologically, place is not the physical environment separate from people associated with it but, rather, the indivisible, normally unnoticed phenomenon of person-or-people-experiencing-place" (Seamon, 2014, p. 11).

24 "Places are experienced as an extension of the self" (Brown; Perkins, 1992, p. 282). 
trocado, mas um centro irrevogável de significância". ${ }^{25}$ Neste nexo, o fenômeno do lar como forma específica de lugar é um palimpsesto de geograficidade experienciada pelo corpo-sujeito em que os significados emergem como transcendência à frieza do universo.

Nessa projeção sensível que percorre seu microcosmo, a percepção irradia da corporeidade inerente de sua consciência. Pela via do galho esquerdo, antes de sua saída, já penetrava as virtualidades telúricas de sentir o lugar. Na casa velha, em comunhão incestuosa com Ana, o protagonista descreve que: "sentindo meus pés descalços na umidade do assoalho senti também meu corpo de repente obsceno, surgiu, virulento, um osso da minha carne, eu tinha esporas nos meus calcanhares, que crista mais sangüínea, que paixão desassombrada, que espasmos pressupostos!" (Nassar, 1989, p. 101).

A experiência sensória do pé desnudo que encosta e sente o úmido desejo do assoalho percorre seu corpo, arrepia seus pelos e evoca respostas telúricas. Simultaneamente, junta-se ao mundo das criaturas da lavoura ao manifestar esporas, cristas e ossos expostos. Sua percepção transfigura a gestalt que sintomatiza o mundo vivido e sua corporeidade nas fronteiras do lugar. Pela via perceptiva metamorfoseia a geograficidade do habitar para potencializar sua própria virulência.

A irreverência corporal do contato que irradia do ato incestuoso modela campos perceptivos. Para Delancey (2006, p. 373, tradução nossa), "como nossas habilidades para a ação moldam a percepção, que é como experienciamos ser-no-mundo, nossas habilidades para a ação simbólica fazem-nos capazes de, em certo grau, moldar nosso mundo e o que somos nesse mundo". ${ }^{26}$ Pela transformação encaminhada na lógica de ser-no-lar, André maximiza a passionalidade do seio materno na lavoura e reposiciona a tensão como elemento definidor do lugar.

Hoyaux (2003, p. 8, tradução nossa) reafirma essa centralidade acional do corpo ao salientar que "o lugar recupera o local da entidade corporal (estando disponível) ou carnal (outro ser-no-mundo) por meio do ser-no-mundo que se projeta em sua preocupação ou atenção" . ${ }^{27}$ Essa inseparabilidade de sua carnalidade intersubjetiva realça a gestalt na qual se sobrepõem os fundamentos do lugar. A ação projeta o habitar para a dinamicidade do devir. Entremeio à entidade corporal que forma o núcleo da revolta do galho esquerdo existe, logo, outra proposta de ser-no-lar.

Na perspectiva de Merleau-Ponty (2014, p. 132) o corpo é aquilo que "nos une diretamente às coisas por sua própria ontogênese, soldando um a outro os dois esboços de que é feito, seus dois lábios: a massa sensível que ele é e a massa do sensível de onde nasce por segregação, e à qual, como vidente, permanece aberto". É, portanto, nessa possibilidade sinestésica de transcendência que o lugar se expande como gestalt de ordenamento do mundo. No conflito das diferentes vertentes da família, a vontade de expressividade do corpo anuncia-se pela sua radicalização na via da tragédia que desconfigura a ordem do patriarca.

25 "Home is not just the house you happen to live in, it is not something that can be anywhere, that can be exchanged, but an irreplaceable centre of significance" (Relph, 1976, p. 39).

26 "Since our abilities for action shape perception, which is how we experience being-in-the-world, our abilities for symbolic action make us capable of, to some degree, changing our world and what we are in that world" (Delancey, 2006, p. 373).

27 "Le lieu recouvre la place de l'entité corporelle (étant disponible) ou charnelle (autre être-au-monde) auprès de laquelle l'être-au-monde se projette dans sa préoccupation ou sa sollicitude" (Hoyaux, 2003, p. 8). 
Se, como destaca Merleau-Ponty (2014, p. 121), "o mundo e eu somos um no outro, e do percipere ao percipi não há anterioridade, mas simultaneidade ou mesmo atraso", é porque o corpo sensível se corporifica no mundo pela dimensionalidade dos lugares. Por ser situado em realidade geográfica, o lugar é impelido rumo ao corpo de modo a constituir uma situação de habitar na qual a experiência formula horizontes de existência.

No circuito ativo da percepção, André expressa profundidade reativa a Terra. É, contraditoriamente, no espectro que vai de sua angústia até a topofilia que emerge a forma como perceptivamente define o lugar. Sua corporeidade constrói direção e sentido para o habitar, tornando-o potencial abrasivo e geograficidade que reúne campos da experiência de mundo. $\bigcirc$ microcosmo existencial dessa relação destrincha que entre o corpo-sujeito e o lar existem geografias afetivas que transbordam em estéticas expressivas do ser-no-mundo.

\section{Colheita e indagações}

No campo de Geografia e literatura, a imersão nos espaços diegéticos possibilitou uma perspectiva de aproximação artístico-científica para a compreensão das espacialidades existenciais. Concernente a isso, compôs-se um modo de decifrar a maneira como os sujeitos-personagens refletem geografias afetivas diversas pelas experiências presentes na narrativa. Entender o lugar na perspectiva de André colabora para entender aspectos emocionais e corporais da geograficidade.

A perspectiva fenomenológico-existencial colaborou para decifrar as diferentes formas de vinculação sujeito-lugar, nas suas ambivalências de sentidos e emoções. As contradições inerentes às percepções e a corporeidade dos habitantes da lavoura desvelam a multiplicidade de conexões existentes no lugar. No cosmo de ser-no-lar, angústias decorrentes da ordem e da moral reverberam na dinâmica da realidade geográfica.

Isso implica a compreensão de que, conceitualmente, lugar pode ser compreendido como um todo complexo derivado das relações indissociáveis da experiência dos sujeitos. As coisas e os sentidos se fundem na corporeidade daqueles que habitam o lugar de maneira recíproca e ativa. Nesse sentido, os vínculos que são estabelecidos no cosmo da existência ecoam como maneiras de significar os espaços em que os sujeitos vivem.

$\bigcirc$ habitar, na condição de núcleo perceptivo da geograficidade humana, compõe-se como necessidade de vir a ser nas fronteiras do mundo vivido. Como fenômeno ativo da intencionalidade humana, é manifesto como modo intersubjetivo de se relacionar com a realidade geográfica. Pelos vínculos existenciais estabelecidos, há algo particular no cosmo significado por essa gênese originária.

Na lavoura, o lar é um núcleo de habitar que dinamiza as condições de expressão dos sujeitos. Como ser-no-mundo, os personagens digladiam nos limites entre a submissão da força desejante afetiva e o refreamento que é imposto. Em meio às contradições das lógicas das diferentes vertentes da família no lugar, os galhos esquerdo e direito conformam propostas opostas de fazer-lugar. Contudo, ambos irradiam do mesmo tronco originário centrado no lavrar.

Corporificados, os sujeitos sentem e transbordam emocionalmente as espacialidades que os cercam. A relação dinâmica corpo-laré, portanto, caminho para decifrar a existência no lugar. Como expresso nas descrições e vivências de André, o circuito ativo da percepção é uma potencialidade que funde sujeito-lugar nas condições emergentes de ser-no-mundo. 
Na carnalidade inerente à forma como corpo e experiência se introjetam, explicita-se o lugar como continuidade estendida pela percepção que é formulada no limiar da intencionalidade. Como fenômeno inseparável do sujeito, o lugar é situação primal do habitar humano. Na dinamogenia de ser-no-lar, arquiteta-se que essa junção inexorável é suma de geografias que faz com que seja possível transcender as materialidades do universo ao transformá-lo em microcosmo significante.

Elemento definidor do lugar na lavoura, a tensão expressa a maneira pela qual as diferentes geografias afetivas cartografam o mundo habitado. $\bigcirc$ lar se metamorfoseia pelos contornos do sofrimento de André no que concerne às situações vivenciadas. Ao mesmo tempo, o protagonista mantém topofilias ao lar. Isso desvela que as contradições dos sentimentos são elementos integrais do amplo espectro do lugar. Portanto, ser humano é amar, ser injusto, sofrer ou vivenciar alegrias, e o lugar também se faz nessa amplitude emotiva do ser-no-mundo que a ele dá significado.

\section{Referências}

ABATI, H. M. F. Da Lavoura arcaica: fortuna crítica, análise e interpretação da obra de Raduan Nassar. Dissertação (Mestrado em Letras) - Universidade Federal do Paraná, Curitiba, 1999.

BROWN, B. B.; PERKINS, D. D. Disruptions in place attachment. In: ALTMAN, I.; LOW, S. M. (Org.). Place Attachment. New York: Plenum, 1992. p. 279-304.

CARR, D. Time zones: phenomenological reflections on cultural time. In: CARR, D.; CHAN-FAI, C. (Org.). Contributions to phenomenology: Space, Time and Culture. Amsterdan: Springer Science+Business, 2004. p. 3-14.

CASEY, E. S. The Fate of place: a philosophical history. Berkley: University of California Press, 1998.

DARDEL, E. O homem e a terra. São Paulo: Perspectiva, 2011.

DAVIDSON, J.; MILLIGAN, C. Embodying emotion sensing space: introducing emotional geographies. Social E Cultural Geography, v. 5, n. 4, p. 523-532, 2004.

DELANCEY, C. Action, the scientific worldview, and Being-in-the-world. In: DREYFUS, H. L.; WRATHALL, M. A. (Org.). A companion to phenomenology and existentialism. Malden, MA: Blackwell, 2006. p. 31-47.

HOYAUX, A. De l'espace domestique au monde domestique: point de vue phénomenologique sur l'habitation. In: CLOLLINGNON, B.; STASZAK, J. (Org.). Espaces domestiques: construire, habiter, représenter. Paris: Bréal, 2003. p. 1-12.

HUFFORD, M. Thresholds to an Alternate Realm: mapping the chaseworld in New Jersey's Pine Barrens. In: ALTMAN, I.; LOW, S. M. (Org.). Place Attachment. New York: Plenum, 1992. p. 231-252. 
HUMMON, D. M. Community Attachment: local sentiment and the sense of place. In: ALTMAN, I.; LOW, S. M. (Org.). Place Attachment. New York: Plenum, 1992. p. 253278.

LARSEN, S. C.; JOHNSON, J. T. Toward an open sense of place: Phenomenology, affinity, and the question of being. Annals of the Association of American Geographers, v. 102, n. 3, p. 632-646, 2012.

MARANDOLA JR., E. J.; OLIVEIRA, L. Geograficidade e espacialidade na literatura. Geografia, Rio Claro, v. 34, n. 3, p. 487-508, 2009.

MERLEAU-PONTY, M. O visível e o invisível. São Paulo: Perspectiva, 2014.

MERLEAU-PONTY, M. A prosa do mundo. São Paulo: Cosac Naify, 2012.

MERLEAU-PONTY, M. Fenomenologia da percepção. São Paulo: Martins Fontes, 2011.

MORRIS, D. The sense of space. Albany: State University of New York Press, 2004.

MOTA, B. C. Raduan Nassar e a lavoura dos dizeres: entre provérbios e cantares. Tese (Doutorado em Estudos Literários) - Faculdade de Ciências e Letras, Universidade Estadual Paulista, Araraquara, 2010.

MURCHADHA, F. O. Space, Time and the Articulation of a place in the world: the philosophical context. In: RICHARDSON, B. (Org.). Spatiality and symbolic expression: on the links between Place and Culture. New York: Paulgrave Macmillian, 2015. p. $21-40$.

NASSAR, R. Lavoura arcaica. São Paulo: Companhia das Letras, 1989.

PILE, S. Emotions and affect in recent human geography. Transactions of the Institute of British Geographers, v. 35, n. 1, p. 5-20, 2010.

RELPH, E. Place and placelessness. London: Pion, 1976.

SEAMON, D. Place attachment and phenomenology: The synergistic dynamism of place. In: MANZO, L. C.; DEVINE-WRIGHT, P. (Org.). Place Attachment: advances in theory, methods and applications. Abingdon: Routledge, 2014. p. 11-22.

SEAMON, D. A phenomenology of Inhabitation: the lived reciprocity between houses and inhabitants as portrayed by American Writer Louis Bromfield. In: SYMPOSIUM ON ARCHITECTURE IN THE HUMANITIES, 2008, Huston, TX. Anais... Huston: Association of Collegiate Schools of Architecture (ACSA), 2008.

SEAMON, D. A Geography of the lifeworld: movement, rest and encounter. London: Croom Helm, 1979.

SEAMON, D.; MUGERAUER, R. Dwelling, Place and environment: an introduction. In: SEAMON, D.; MUGERAUER, R. (Org.). Dwelling, place and environment: towards a phenomenology of person and world. Dordrecht, NL: Martinus Nijhoff, 1985. p. 1-14. 
TUAN, Y. Espaço e lugar: a perspectiva da experiência. Londrina, PR: Ed. UEL, 2013.

TUAN, Y. Humanist Geography: an individual's search for meaning. Staunton: George F. Thompson, 2012a.

TUAN, Y. Topofilia: um estudo da percepção, atitudes e valores do meio ambiente. Londrina, PR: Ed. UEL, 2012b.

TUAN, Y. Passing strange and wonderful: aesthetics, nature and culture. New York: Island, 1995.

TUAN, Y. Segmented Worlds and Self: Group life and individual consciousness. Minneapolis, MN: University of Minnesota Press, 1982. 